\title{
Electrochemical Deposition of Copper on Polymer Fibers
}

\author{
Seung-Lin Lim ${ }^{1,2}$, Jaecheon Kim ${ }^{1}$, Jongdeok Park ${ }^{1}$, Sohee Kim², and Jae-Joon Lee ${ }^{1, *}$ \\ ${ }^{1}$ Departmaent of Energy \& Materials Engineering, Dongguk University, Seoul, 100-715, Korea \\ ${ }^{2}$ Nanotechnology Research Centre \& Department of Applied Chemistry, Konkuk University, Chungju 380-701, Korea
}

\begin{abstract}
In this study, we report the fabrication of functional complex fibers, which have been studied widely globally for numerous applications. Here, we fabricated conductive complex fibers with antibacterial properties by coating metal ions on the surface of plastic (polypropylene) fibers using the electroless and electrochemical deposition. First, we polished the polypropylene melt-blown fiber surface and obtained an absorbing Pd seed layer on its surface. Subsequently, we substituted the Pd with $\mathrm{Cu}$. Bis-3-sulfopropyl-disulfide disodium salt (SPS), polyethylene glycol (PEG), and ethylene thiourea (ETU) were used as the brightener, carrier, and leveler, respectively for the electroplating. We focused on most achieving the stable plating condition to remove dendrites, which are normally during electroplating metals so that smooth layer is formed on the fiber surface. The higher the amount of SPS, the higher was the extent of irregular plate-like growth. Many irregularities in the form of round spheres were observed with increase in the amount of PEG and ETU. Hence, when the additives were used separately, a uniform coating could not be obtained. A stable coating was obtained when the three additives were combined and a uniform 5-9 $\mu \mathrm{m}$ thick copper layer with a stable morphology could be obtained around the fiber. We believe that our results can be applied widely to obtain conductive fibers with antibacterial properties and are useful in aiding research on conductive lightweight composite fibers for application in information technology and robotics.
\end{abstract}

Keywords : Electroless plating, Electrochemical plating, brightener, Carrier, Leveler

Received : 10 February 2016, Revised : 25 April 2016, Accepted : 25 April 2016

\section{Introduction}

The fiber industry, which is one of the oldest industries in the human history, has undergone various changes so far and functional and industrial fibers are expected to dominate the field in future. The fiber industry of the $21^{\text {st }}$ century is predicted to experience a high growth rate of $>6 \%$ per annum by 2025 because of the development of functional and industrial fibers, which will find wide applications in environmental and information technology-related sectors. The competition within the fiber industry is expected to increase because of international labor division and trade liberalization. Developing nations are expected to make rapid progress in the traditional fiber industry sector because of the abolition of the

*E-mail address: jjlee@dongguk.edu

DOI: http://dx.doi.org/10.5229/JECST.2016.7.2.132 fiber quota system, and the importance of China is expected to rapidly grow, with its membership in the World Trade Organization. On the other hand, for industrial and functional fiber sectors, which are considered high value added and high-tech businesses, the investment on research and development and technology competition has become stupendously increased among advanced countries such as Korea.

With changes in the trends of the world fiber market, future fiber industry products, and fiber technology, Korea has already begun to develop functional fibers in earnest, spurred by interest from the government. Various types of functional fibers were developed for application in nanotechnologies, various digital and smart industries, artificial intelligence, and biomedical engineering. For biomedical applications, the demand for antibacterial products, which purify air and liquid, has increased drastically because of an increased interest in environment and hygiene. The 
world market size of antibacterial products reached 3.4 billion US dollars in 2000 and is rapidly growing over $15 \%$ every year. The market size in Korea, which was about 350 billion KRW in 2000, shows a more rapid growth than the world market. The air filter market can be divided into products used for in-house use, such as air conditioners and air cleaners, and those for industries, such as industrial heating, ventilating, and air conditioning filters, and air conditioning products used in automobiles. The demand of air cleaners shows a steady growth despite the slower sales of home appliances during economic depression [1]. In addition, due to the increased demand for products enhancing a healthy life, the domestic market size of water purifiers has increased to 1 trillion KRW and many home appliance producers are investing in the water purifier market as a new business with market shares of $60 \%$ for simple water purifier, $30 \%$ for mineralized water purifier, and $10 \%$ for processing some specially functionalized water. The trend shows an increase of market for pure water bestowing health benefits and the potential of functionalized water market is much larger than the other industries.

In this study, we have used electroless plating without organic and inorganic binders to obtain antibacterial non-woven fabrics for water filter applications, exhibiting stronger antibacterial activity than existing antibacterial non-woven fabrics. Deposition of metallic ions on fiber surfaces using the electroless plating method has been widely studied. For effective plating, various methods, such as the use of ethylenediaminetetraacetic acid, formaldehyde, and organic additives [2-4] and injecting of various reducing agents, such as hydrazine, sodium hydride, sodium citrate, and diethylamineborane into the plating solution have been used [5-8]. There are many studies focusing on replacing the conventionally used, but expensive, $\mathrm{Pd}$ [9]. However, in this research, $\mathrm{Pd}$ plating was used to achieve a basic adhesive strength by creating a seed layer on the clean fiber at the first stage of plating [10-13]. Subsequently, various organic additives were added to the seeded layer to control deposition of metal from metal ions to obtain a layer with the required fine structure $[14,15]$.

\section{Experimental Section}

\subsection{Electroless plating of $\mathrm{Cu}$}

Plating baths were equipped with a heater and con- troller and separate baths were used for each process because the differences in the chemicals and temperature required for each process. Spunbonded polypropylene non-woven fabric $\left(60 \mathrm{~g} / \mathrm{m}^{2}\right.$, Toray $)$ and Spunbonded polyester nonwoven fabric $\left(60 \mathrm{~g} / \mathrm{m}^{2}\right.$, Dongyang), the most common fibers in the fabric industry, were used as the test samples. Samples were soaked in $\mathrm{NaOH}$ at $70^{\circ} \mathrm{C}$ for $3 \mathrm{~min}$ for degreasing. Then, the samples were soaked in another bath with $\mathrm{KMnO}_{4}$ and $\mathrm{H}_{2} \mathrm{SO}_{4}$ for $5 \mathrm{~min}$ at $70{ }^{\circ} \mathrm{C}$ to polish the surface to achieve an anchoring effect. Then, the samples were cleaned with $\mathrm{H}_{2} \mathrm{C}_{2} \mathrm{O}_{4}$ to remove the acid radicals and dipped in a $\mathrm{PdCl}_{2}-\mathrm{HCl}$ solution for 5 min to activate $\mathrm{Pd}$ substitution of the already formed Sn layer [16]. Then, electroless $\mathrm{Cu}$ plating was carried out for $20 \mathrm{~min}$ in a bath containing $\mathrm{CuSO}_{4}, \mathrm{NaH}_{2} \mathrm{PO}_{2}, \mathrm{NiSO}_{4}$, and $\mathrm{Na}_{3} \mathrm{C}_{6} \mathrm{H}_{5} \mathrm{O}_{7}$ at an appropriate concentration (as shown in Table 1) $[17,18]$. The reduction potential of each element is shown below.

$$
\begin{array}{ll}
\mathrm{C}_{u}^{2+}+2 e \rightarrow \mathrm{Cu} & E_{\mathrm{Cu}^{2+} / \mathrm{Cu}}=0.34 \mathrm{~V} \\
\mathrm{Ni}^{2+}+2 e \rightarrow \mathrm{Ni} & E_{\mathrm{Ni}^{2+} / \mathrm{Ni}}^{0}=-0.25 \mathrm{~V} \\
\mathrm{H}_{2} \mathrm{PO}_{2}^{-}+e \rightarrow \mathrm{P}+2 \mathrm{OH}^{-} & E^{0}=-1.82 \mathrm{~V}
\end{array}
$$

The surface of the fiber and plated copper particles were analyzed using SEM (scanning electron microscopy) and EDX (energy dispersive X-ray spectroscopy) to obtain the morphology and composition of the electrodeposited particles, respectively.

\subsection{Electrodeposition}

Electroplating was carried out by including bis-3sulfopropyl-disulfide disodium salt (SPS), polyethylene glycol (PEG), and ethylene thiourea (ETU) as the brightener, carrier, and leveler, respectively to the aqueous copper sulfate solution with 50 ppm $\mathrm{Cl}^{-}$. The additives were used to control the growth rate of copper during deposition [14,20,21]. A rectifier was used as the plating equipment and $\mathrm{Pt}$ anode and biodegradable polypropylene nonwoven fabric with electroless plated copper cathode were used. The experiment was carried out at room temperature in a glass beaker, which served as the electrolyte bath.

After deposition, the test samples ( $1 \mathrm{~cm}$ wide and $4.5 \mathrm{~cm}$ tall) were dipped into $100 \mathrm{~g} / \mathrm{L}$ of aqueous sul- 
furic acid for $2 \mathrm{~s}$. Then, the samples were rinsed with water for $30 \mathrm{~s}$ to remove foreign substances. To the best of our knowledge, not many studies focus on electroplating common fibers for filter applications. Therefore, we have changed the plating solution to match the conventional concentration used and we have used additives known to modulate the electrodeposition speed and other characteristics. The bath conditions used here are provided in Table 2. A low current density was used because plating within the fiber does not occur at high current densities because of an increase in the throwing power. When the plating leads to an excessively thick coating, the flow rate sharply decreases because the distance between the fibers decreases. Accordingly, the plating time was adjusted to obtain thin coatings with a thickness of 20-25 $\mu \mathrm{m}$. To minimize the number of variables, the copper and sulfuric acid concentrations were fixed. SPS is known to increase the plating speed and PEG enables electrodeposition in the deeper portions of the objects by preventing leaning and flowing of current. Table 1 shows the correlation between the electrodeposition conditions such that the most optimal plating can be achieved [20]. The theoretical amount of electrodeposition is calculated by limiting the area of the cathode. We confirmed that the fiber was well deposited overall, and the amount of electrodeposition was also determined using SEM. SEM was also used to characterize the fiber surface and the plated particles, while the composition of the electrodeposited particles was analyzed by EDX. The antibacterial activity of the obtained fiber was determined using Staphylococcus Aureus ATCC and 6538 Staphylococcus Aureus ATCC 6538.

\section{Results and Discussion}

\subsection{Effect of plating time on the morphology of} the electroless plated layer

Metals can be deposited on a non-conductive fiber surface regardless of the fiber type after degreasing and etching (Fig. 1) [19]. The bath conditions shown in Table 1 are the conditions used for the electroless plating of polyesters like polyethylene terephthalate, which is the most widely used industrial plastic fiber, and spunbonded polypropylene. While it is known that the amount of material electrodeposited increases with time, the SEM-EDX analysis reveals hardly any change in the morphology and composition. Hence, changing the electrodeposition time leads to changes in the amount of materials deposited, while the composition remains unaffected. However, increasing the thickness by increasing the plating time is not required during electroless plating because the thickness and the antibacterial activity can be increased during the subsequent electroplating step. In addition, if an excessively long time is used for obtaining the seed layer, loss of uniformity is observed, which may lead to the growth of unnecessary structures, which in turn lead to removal of plated layers, affecting the subsequent electroplating step. Hence, it is advisable to keep the electroless plating time short to obtain the minimum amount of seeds required.
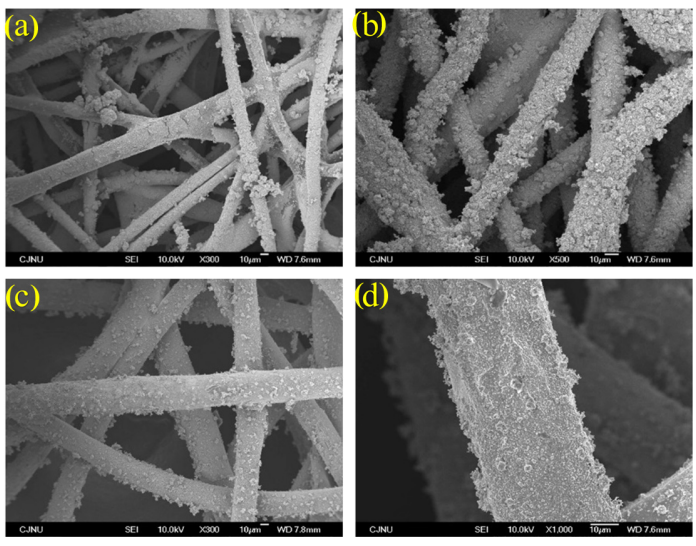

Fig. 1. Scanning electron microscopic (SEM) images of electroless plating of $\mathrm{Cu}$ on the surface of $(\mathrm{a}, \mathrm{b})$ polyester and $(\mathrm{c}, \mathrm{d})$ polypropylene.

Table 1. Bath and operating conditions of electroless plating.

\begin{tabular}{ccccccc}
\hline \hline \multirow{2}{*}{$\begin{array}{c}\text { Bath } \\
\text { conditions }\end{array}$} & Reagents & $\mathrm{CuSO}_{4} \cdot 5 \mathrm{H}_{2} \mathrm{O}$ & $\mathrm{NaH}_{2} \mathrm{PO}_{2}$ & $\mathrm{NiSO}$ & $\mathrm{H}_{3} \mathrm{BO}_{3}$ & $\mathrm{Na}_{3} \mathrm{C}_{6} \mathrm{H}_{5} \mathrm{O}_{7}$ \\
\cline { 2 - 6 } & Concentration $(\mathrm{g} / \mathrm{L})$ & 8 & 30 & 1 & 10 & 10 \\
\hline \multirow{2}{*}{$\begin{array}{c}\text { Operating } \\
\text { conditions }\end{array}$} & $\mathrm{pH}$ & 4 & 9 & 70 & 11 \\
& Temperature $\left({ }^{\circ} \mathrm{C}\right)$ & 70 & 20 & 20 & 70 \\
\hline
\end{tabular}




\subsection{Effect of pH on the morphology of electroless plated samples}

The composition and structure of the plated layers
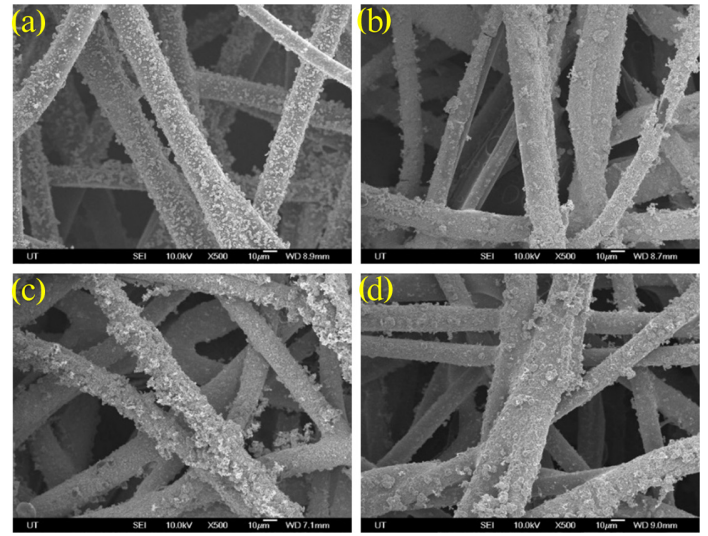

Fig. 2. SEM images of electroless plated samples obtained at different $\mathrm{pH}$ of (a) 4, (b) 9, (c) 10 and (d) 11.

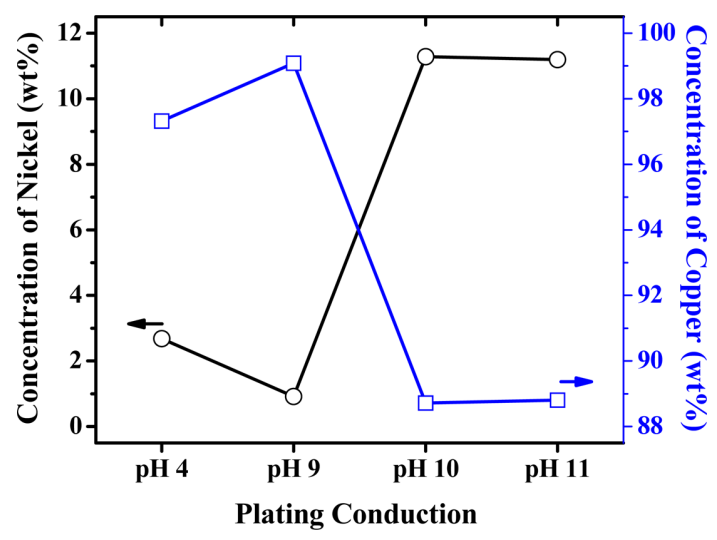

Fig. 3. Elemental analysis estimated from energydispersive X-ray (EDX) spectroscopy of samples obtained by electroless plating at different $\mathrm{pH}$. are dependent on the $\mathrm{pH}$ change during electroless plating partly because of the variation of the concentration of the major metallic component in the electrolyte $[3,17]$. As shown in Fig. 2 and 3, the EDX analysis shows that the copper content in the plated sample is highest when the plating solution $\mathrm{pH}$ is 10 . Hence, the optimal condition for copper plating can be identified.

\subsection{Effect of additives}

In general, the brightener, carrier, and leveler are used as electroplating additives [14]. In the present study, we used a plating solution with conventionally used copper sulfate and sulfuric acid [14,15] and the concentration of the additives was fixed at 5-20 ppm (Table 2) [20]. We compared the morphology of copper deposited on fibers when the additives were used separately and when none of the additives were used. Without additives, the copper deposited was irregular and unstable and a similar structure was obtained when only the brightener was added. The copper was deposited in acicular shapes when the leveler and carrier were added. Hence, when the additives were used individually, unstable and nonuniform products, as shown in Fig. 4, were obtained. While the brightener agglomerates particles to form larger clusters, the leveler and carrier break the copper particles into smaller pieces.

\subsection{Effect of the brightener}

The brightener was added separately to the bath to obtain find the optimal brightener concentration during electrodeposition. As shown in Fig. 4, unstable electrodeposition and structures resembling spilt keratins were obtained when the SPS concentration was 1,5 , or $10 \mathrm{ppm}$. The number of overgrown nodules increased at $20 \mathrm{ppm}$ and stable and evenly plated layers were obtained at $15 \mathrm{ppm}$.

Table 2. Bath and operating conditions of electroplating with different concentration of additives.

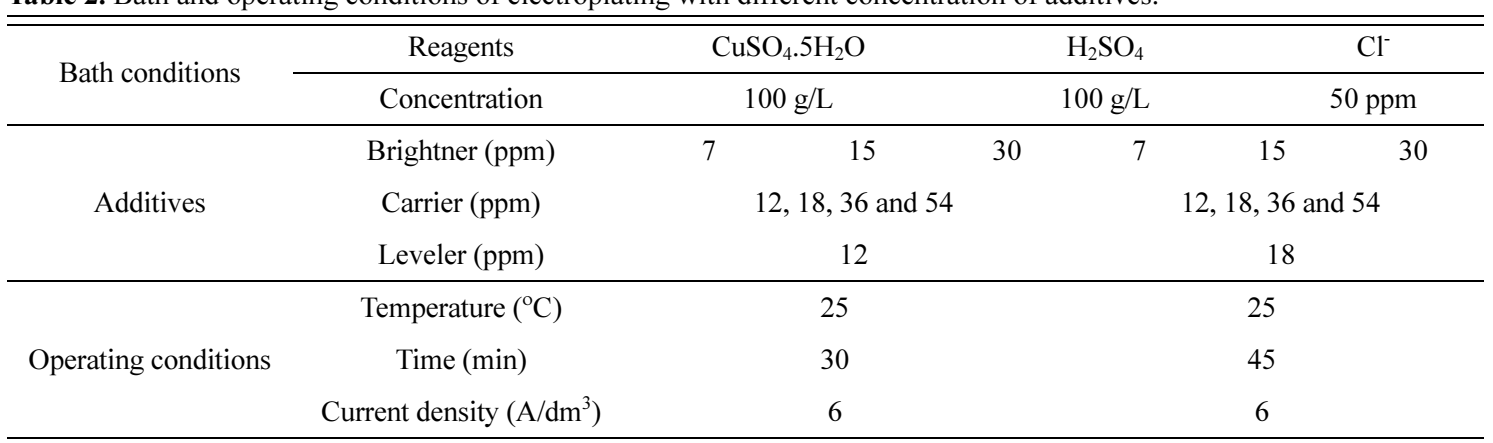




\subsection{Effect of the carrier : leveler ratio}

The experiment was carried out with the conventionally used brightener: (leveler + carrier) ratio of $1: 2$. As noted previously, $15 \mathrm{ppm}$ of brightener leads to stable electrodeposition; however, the amount of carrier + leveler should be maintained at $30 \mathrm{ppm}$, while changing the ratio of the two additives (Fig. 4). A ratio of 3: 2 (Fig. 4d) leads to the most stable surface, while other ratios lead to keratin-like shapes or fine cracks on the surface. The optimum ratio (3:2) of the two additives was advantageous to deposit $\mathrm{Cu}$ on the front fibers uniformly and effectively, resulting in smooth and homogeneous $\mathrm{Cu}$-coated surface, however, the deposition of $\mathrm{Cu}$ on the rear or deeper fibers was irregular and non-uniform due to the drop of chemical potential in the fibers at the deeper level.

\subsection{Effect of plating time and composition of additives on the morphology}

Changes in the structure of the deposited surface were observed by changing the concentration of each additive by $10 \%$. Further, the structural changes with variation of plating times were analyzed simultaneously. The surface magnified to 500 times became irregular and showed unstable growth when the leveler and carrier were used in excess, while the deposition was stable when the brightener concentration was low. We confirmed that the surface that appeared stable when magnified to 500 times was irregular and
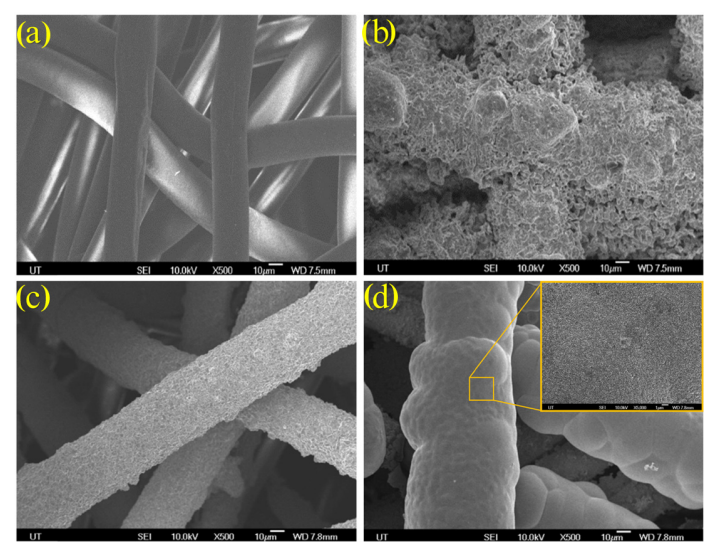

Fig. 4. SEM images of (a) polypropylene (PP) fibers, (b) PP fibers after electroplating of $\mathrm{Cu}$ without additives, (c) PP fibers after electroplating of $\mathrm{Cu}$ using only the brightener at 15 ppm, and (d) PP fibers after electroplating of $\mathrm{Cu}$ using carrier:leveler ratio at $12 \mathrm{ppm}: 18 \mathrm{ppm}(3: 2, \mathrm{v} / \mathrm{v})$. unstable when magnified to 5000 times (Fig. 5). The overall surface morphology did not change significantly when the thickness increased with increase in plating time.

\subsection{Optimization of additives}

To identify the effect of plating conditions, the morphology of the copper layer deposited on the fiber was analyzed for various electrochemical $\mathrm{Cu}$ plating conditions without any additives and with different concentrations of the brightener, leveler, and carrier. When the leveler and carrier were used together, the structure of the deposited copper changed to an acicular form. Hence, the brightener leads to agglomeration of the particles, while the leveler and carrier breaks copper particles into smaller pieces. The brightener concentration required to achieve the most stable electrodeposition was obtained by modulating the relative ratio in the initial values used. The most stable deposit was achieved when the concentration was $<10 \mathrm{ppm}$. When the concentration exceeded $30 \mathrm{ppm}$, bumpy structures were obtained on the fiber and irregular growth with fine structures was observed. In addition, the levelercarrier ratio required to achieve the most stable electrodeposition was also optimized to reduce irregular growth, defects, and fine structure. The most stable electrodeposition was achieved when the amount was raised to $200 \%$ (Fig. 6).
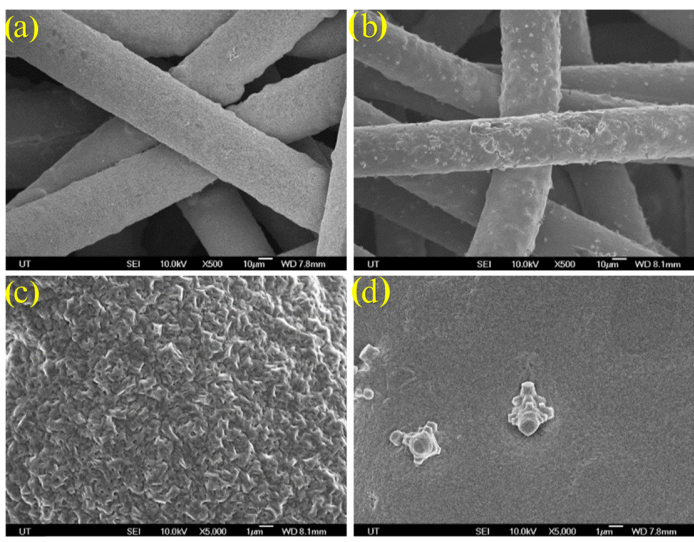

Fig. 5. Changes in the SEM morphologies as a function of the plating time and additives concentration (a) SPS 16.5 ppm, PEG 18 ppm, ETU 12 ppm, (b) SPS 15 ppm, PEG 20 ppm, ETU 14 ppm and deposition time $=30 \mathrm{~min},(\mathrm{c}$ and $\mathrm{d})$ the samples were obtained under the same conditions with deposition time of $45 \mathrm{~min}$. 

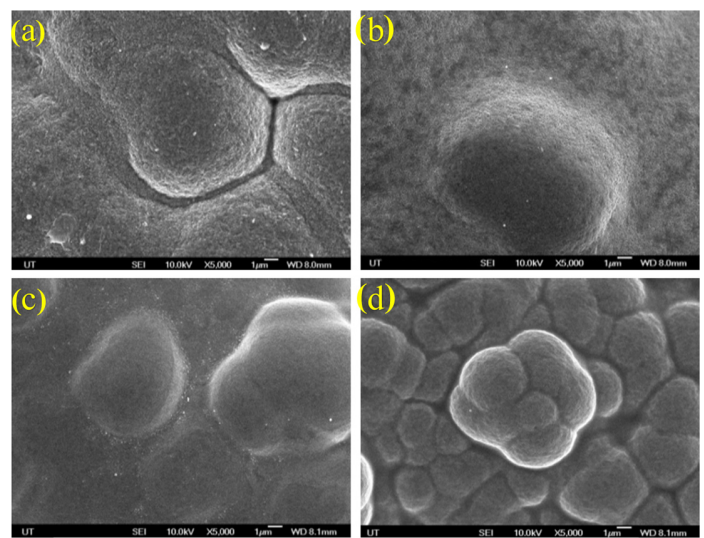

Fig. 6. SEM morphologies after changing the concentrations of brighteners at (a) $5 \mathrm{ppm}$, b) $15 \mathrm{ppm}$, and total concentration of the carrier + leveler $(3: 2, \mathrm{v} / \mathrm{v})$, (c) $30 \mathrm{ppm}$ and (d) $60 \mathrm{ppm}$.
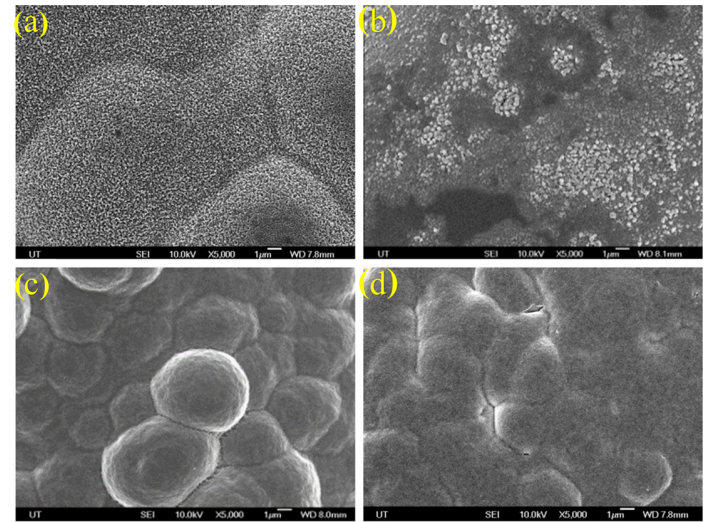

Fig. 7. SEM Morphologies changing as a function of the additive concentrations (a) $50 \%$ decrease in comparison to the conventional ratio, (b) conventional ratio (SPS $15 \mathrm{ppm}$, PEG $18 \mathrm{ppm}$, and ETU $12 \mathrm{ppm}$ ), (c) $200 \%$ total increase, and (d) brighter $200 \%$, leveler + carrier $210 \%$.

\subsection{Optimization of the ratio of additives}

Fine structure was less fine and much defects were found when the amount of additives was lower than the conventional values used. When the amount of brightener was further increased by $10 \%$ after increasing the amount of brightener by up to $200 \%$, the fine structure was unstable. In contrast, when the amount of leveler and carrier was increased to more than $210 \%$ to $300 \%$, stable plating was achieved (Fig. 7). The plated layer thickness varies with plating time and in this study, a deposition thickness of about $27 \mu \mathrm{m}$ is achieved on a flat layer. Under the
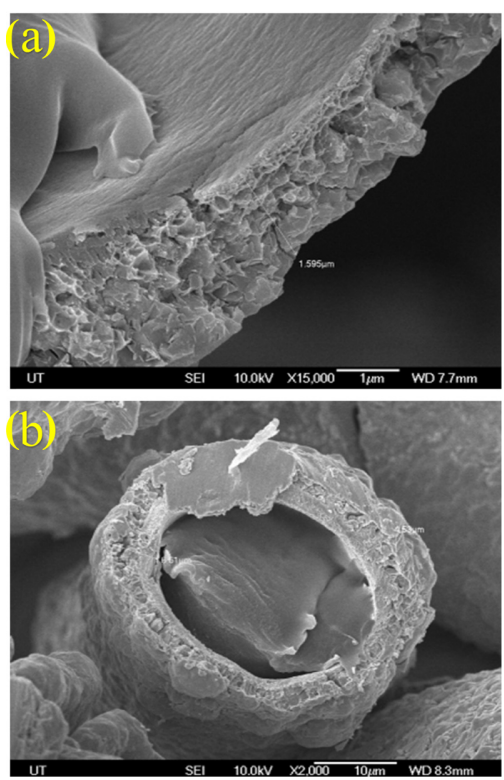

Fig. 8. SEM images of the section morphology after electroless plating and electroplating. (a) Cross-section of electroless plated fiber (thickness $1.6 \mu \mathrm{m}$ ) and (b) the crosssectional image of the electroplated fiber (thickness 4.6 6.6 $\mu \mathrm{m})$.

same conditions, a 4-6.5 $\mu \mathrm{m}$ thick copper layer is deposited on the surface of a round fiber. The difference is because the fiber surface is not flat and copper particles penetrate into non-woven fiber and layer obtained after each deposition is thin. The difference in fibers can also be attributed to the gap of strength, which receives current (Fig. 8).

\section{Conclusions}

This research aimed to deposit stable structured copper layers on polypropylene spun yarn non-woven fabric fiber by electroless deposition to seed copper and by a subsequent electroplating step. In electroless plating, the copper structure and composition varied with the $\mathrm{pH}$ of the plating solution. The morphology and composition of the electrodeposited copper were characterized by SEM and EDX and the optimum plating conditions were identified. The additives, including a brightener, leveler, and carrier were used for the electrodeposition. The specific roles of these additives were identified by analyzing the structure and morphology of the elecrodeposition. A low current density of $6 \mathrm{~A} / \mathrm{dm}^{2}$ was used because the 
deposits are required to penetrate into the fiber, while maintaining plating on the outerlayers. The observed results indicate that stable plating cannot be achieved when the three additives were used individually and the conventionally used composition of these additives is not applicable to plastic fibers. Leveling is achieved when the leveler and carrier concentrations (in comparison to conventional concentrations) were increased to $>200 \%$. Electroless plating led to a copper layer with a thickness of $1.5 \mu \mathrm{m}$ and electroplating resulted in a stable plated layer, 4-6.5 $\mu \mathrm{m}$ in thickness. We predict that a denser copper layer can be formed from electroplating with a bath using lesser concentration of additives if a denser and more uniform seed layer can be obtained by changing the temperature during electroless plating or by altering the Ni concentration in the plating bath $[3,17]$. In terms of the brightener, the monosulfide series of additives is known to increase the flexibility by changing the structure of plated layers. It is expected that we can achieve improved results if more appropriate concentration and plating conditions can be used in the two steps.

\section{Acknowledgements}

This work was supported by the New \& Renewable Energy Core Technology Program of the Korea Institute of Energy Technology Evaluation and Planning(KETEP) granted financial resource from the Ministry of Trade, Industry \& Energy, Republic of Korea (No. 20133030000140) and by National Research Foundation of Korea (NRF) funded by the Ministry of Education (2013R1A1A4A01013236, 2015M1A2A2054996).

\section{References}

[1] C.-W. Park, Y.-H. Yoon and J. Hwang, PAAR, 2010, $6(2), 69-80$.
[2] H. Zhang, X. Zou and J. Sun, J. Compos. Mater, 2012, 46(24), 3001-3009.

[3] G. Venkatachalam, S. Kanthikeyan, M. Hitharth, K. Sumanjeet and S. Narayanan, Int. J. ChemTech Res., 2013, 5(1), 237-245.

[4] J. Li and P. A. Kohl, J. Electrochem. Soc., 2002, 149 (12), C631-C636.

[5] M. L. Bosko, F. A. Marchesini, L. M. Corraglia and E. E Miró, Catal. Today, 2013, 212, 16-22.

[6] W. Kang, Q. Li, B. Cheng, Y. Ren and X. Zhuang, 3rd International Nanoelectronics Conference (INEC); 2010 Jan. 3-8, IEEE, 415-416.

[7] K. G. Mishra, and R. K. Paramguru, Afr. J. Pure Appl. Chem., 2010, 4(6), 87-99.

[8] B. Kim, S. H. Jung, S. W. Suh and B. K. Park, J. Nanosci. Nanotechnol., 2013, 13, 517-522.

[9] Y. Lu, Q. Liang and L. Xue, Appl. Surf. Sci., 2012, 258, 4782-4787.

[10] L.-S. Son, H.-N. Lee and H.-K. Lee, J. Kor. Inst. Surf. Eng., 2012, 45(1), 8-14.

[11] R. H. Guo, S. Q. Jiang, C. W. M. Yuen, and M. C. F. Ng, J. Mater. Sci.: Mater. Electron, 2009, 20, 33-38.

[12] L.-S. Li, X.-R. Li, W.-X. Zhao, Q. Ma, X.-B. Lu, and Z.-L. Wang, Int. J. Electrochem. Sci., 2013, 8, 51915202.

[13] Y. Wang, C. Bian, and X. Jing, Appl. Surf. Sci., 2013, 271, 303-310.

[14] J. J. Kelly, C. Tian, and A. C. West, J. Electrochem. Soc., 1999, 146(7), 2540-2545.

[15] W.-P. Dow, and H.-H. Chen, Circuit World, 2004, 30(3), 33-36.

[16] S. B. Yang, B. K. Min, S. D. Choi, and H. J. Shin, J. Korean Inst. surf. Eng., 2001, 34(3), 215-224.

[17] R. H. Guo, S. X. Jiang, C. W. M. Yuen, M. C. F. Ng, J. W. Lan, Y. L. Yeung, and S. J. Lin, Fibers and Polymers, 2013, 14(5), 752-758.

[18] I. S. Oh, J. D. Park, and Y. H. Bai, J. Korean Soc. Power Sys. Eng., 2001, 5(2), 71-78.

[19] M. A. Dinderman, W. J. Dressiok, C. N. Kostelansky, R. R. Price, S. B. Qadri, and P. E. Schoen, Chem. Mater, 2006, 18, 4361-4368.

[20] P. M. Vereecken, R. A. Binstead, H. Deligianni, and P. C. Andricacos, IBM J. RES \& DEV., 2005, 49(1), 3-18.

[21] W.-P. Dow, H.-S. Huang, and Z. Lin, Electrochem. Solid-state Lett., 2003, 6(9), C134-C136. 